\title{
Virgin Natural Cork Characterization as a Sustainable Material for Use in Acoustic Solutions
}

\author{
Juan Miguel Barrigón Morillas ${ }^{1}$, David Montes González ${ }^{1, *(\mathbb{D},}$, Rosendo Vílchez-Gómez ${ }^{1}$,

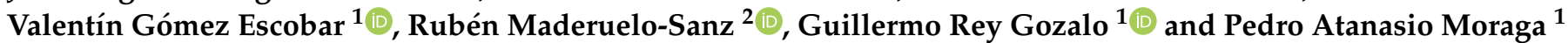

1 Institute for Sustainable Regional Development (INTERRA), Lambda, Departamento de Física Aplicada, Universidad de Extremadura, 10003 Cáceres, Spain; barrigon@unex.es (J.M.B.M.); vilchez@unex.es (R.V.-G.); valentin@unex.es (V.G.E.); guille@unex.es (G.R.G.); pedroam@unex.es (P.A.M.)

2 Instituto Tecnológico de Rocas Ornamentales y Materiales de Construcción (INTROMAC), Campus Universidad de Extremadura, 10071 Cáceres, Spain; ruben.maderuelo@org.juntaex.es

* Correspondence: davidmg@unex.es

check for updates

Citation: Barrigón Morillas, J.M.; Montes González, D.; Vílchez-Gómez,

R.; Gómez Escobar, V.; Maderuelo-Sanz, R.; Rey Gozalo, G.; Atanasio Moraga, P. Virgin Natural Cork Characterization as a Sustainable Material for Use in Acoustic Solutions. Sustainability 2021, 13, 4976. https://doi.org/10.3390/su 13094976

Academic Editor: Roberto Benocci

Received: 26 March 2021

Accepted: 26 April 2021

Published: 29 April 2021

Publisher's Note: MDPI stays neutral with regard to jurisdictional claims in published maps and institutional affiliations.

Copyright: (c) 2021 by the authors. Licensee MDPI, Basel, Switzerland. This article is an open access article distributed under the terms and conditions of the Creative Commons Attribution (CC BY) license (https:// creativecommons.org/licenses/by/ $4.0 /)$.

\begin{abstract}
A characterization of the sound absorption of a sustainable material with scarce current use such as natural virgin cork is presented in this paper in order to explore further possible applications in the design of acoustic solutions. Different samples of virgin cork not bonded and various decorative panel formats were tested under random sound incidence conditions in a standardized reverberation chamber. The samples in which the outer bark of the cork was facing upwards showed a better behavior as an acoustic absorber, with sound absorption coefficient values generally greater than 0.6 for frequency bands between 1 and $5 \mathrm{kHz}$. The results obtained were compared with samples of some recycled materials available in the scientific literature, such as sheep wool and PET.
\end{abstract}

Keywords: sound absorption; reverberation chamber; ISO 354; green circular economy; building material

\section{Introduction}

Global warming and sustainable management of the planet's resources are two major challenges facing society today. Construction is one of the economic activities that most needs to transform production models, given the use of many non-renewable materials and the high carbon footprint of their production. Some acoustic properties of a biomaterial that usually ends up either discarded or reused, but after the addition of petroleum-based binders, are analyzed in this work. This is virgin cork, the bark of the cork oak tree is extracted for the first time.

The cork oak (Quercus suber L.) is a typical tree of the Mediterranean basin, cultivated due to the use of its bark for cork production. Cork oak forests are a model of agricultural exploitation, in which the tree must remain alive for the cork extraction (and, therefore, fixing carbon). Furthermore, a forest can be managed in what is known as a "Dehesa" system (ecosystem consisting of meadow or pasture artificially modified with scattered trees such as holm oaks and cork oaks), which concerns other sustainable activities such as extensive farming (with a lower carbon footprint than intensive), apiculture, mycoculture, etc. [1,2]. Cork can be an excellent product in a Mediterranean green circular economy as it is a renewable and recyclable natural material. It should be noted that its extraction does not cause any negative impact: (a) it does not require cutting down the tree and (b) it does not cause contamination, as it is done carefully by hand.

The cork oak is characterized by continuous growth of the subereous tissue that protects the inner areas of the trunk and branches. Moreover, this external layer can be extracted without the tree dying and the process can be repeated several times during the life of the tree. Cork exploitation has three stages: a first extraction of the bark, known as ordinary virgin cork; a second extraction, known as secondary reproduction cork, with a limited use; and the following extractions [3]. These last two stages are known as 
reproduction cork. The first two extractions (and especially that corresponding to virgin cork) are characterized by producing an irregular cork, both in structure and in thickness and density. It is also quite rough, as it develops deep fractures and cracks that extend irregularly, although generally with a longitudinal orientation. This fact is what gives cork oak trunks and branches their typical striated appearance [4,5]. In addition, virgin cork has a higher volumetric density than reproductive cork [6]. At the cellular level, the cell composition of virgin cork has a higher content of suberin and extractable compounds, such as waxes and fats [5].

The main industrial use of cork is the manufacture of stoppers for wine bottles, although recent studies have shown that the overall environmental impact of cork stoppers in wine bottles is higher than when using screwcaps [7]. Apart from the use for stoppers, other uses of cork are becoming more widespread lately, given its low density, as is the case of its use for the lightening of concrete [8] or lightweight aggregate for cementbased materials [9]. If cork is used as a stopper, a minimum thickness without excessive irregularities or fractures is necessary. This means that virgin cork is discarded for this use. However, since it shares other characteristics of cork from subsequent extractions, such as maintaining its properties over a wide temperature range [10] and not releasing toxic substances in case of fire [5], it can also be used as a thermal and acoustic insulator.

In this regard, the reduction in noise pollution in urban environments is another challenge facing today's society. The European Environment Agency (EEA) has recently published a report showing that $20 \%$ of the European population, i.e., some 113 million people, are exposed to noise levels that are harmful to their health [11]. Prolonged exposure to noise produces a variety of health effects ranging from physiological problems (varying degrees of hearing loss, disturbances during pregnancy, negative effects on the cardiovascular and metabolic system, etc.) to psychological (discomfort, altered mental health, cognitive impairment in children, sleep disturbances, etc.) [12]. The development of materials and solutions that contribute to the improvement of sound insulation of buildings with respect to both environmental noise and community noise between dwellings is an aspect that can positively influence the well-being of citizens $[13,14]$. There is a growing interest in the positive perception of the indoor acoustic environment of a dwelling by the building occupants and in the development of appropriate metrics to evaluate this environment $[15,16]$. To this must be added the growing concern in construction for the use of products that improve the acoustic sensation, but using components that either give a second life to waste materials [17-24], or are eco-friendly [25-29], as is the case of reproduction cork (obtained from the second and subsequent extractions), whose acoustic characteristics were studied in the loose granulated form [30] or compacted with the addition of resins [31].

Along the same lines, and combining both concerns, the use of waste materials and eco-friendly materials, virgin cork can be found. So far, the acoustic absorption coefficient of virgin cork remains uncharacterized, but given the macroscopic and microscopic differences that exist, it is necessary to evaluate this parameter in order to exploit this material in its natural state, as a decorative element with acoustic absorption capacity. As already mentioned, it is a material that currently has little use and therefore little economic value [6]. However, it also has a low carbon footprint, as boiling is the only process to which it is subjected in order to give it a flat shape. In this work, we present a study of its acoustic absorption without crushing it to make agglomerates and, therefore, without adding any type of resins or other binding elements. Experimental tests were carried out in a reverberation chamber to determine its acoustic absorption capacity in actual environments with random sound incidence. In addition, a study is made of the acoustic behavior of a presentation proposal for possible application in indoor environments and, if applicable, its commercialization. 


\section{Methodology}

\subsection{Cork Sample Collection and Treatment}

As said before, cork oak forests play a very important role in preventing soil erosion and subsequent desertification, also acting as key elements in the preservation of biodiversity in the Mediterranean basin, helping to fix population in rural areas given the need for labor due to the scarce mechanization involved in the cork extraction process.

The age at which a cork oak can enter production depends on its radial growth. It can range from 20-25 years in normal conditions, although it can reach 30-40 years in less favorable environments. The time between two consecutive extractions also depends on the area. Thus, in Portugal and southern Spain, a thickness of about $3-3.5 \mathrm{~cm}$ is reached in nine years, while in northern Spain or southern France it takes more than 15 years.

The cork extraction, or cork stripping, is done manually, with two cork strippers per tree who have good technical knowledge to avoid injuring the tree. A special stripping axe with a curved cutting blade and a relatively long wooden arm is used. Some attempts have been made to mechanize the process, but they have been unfeasible for practical or economic reasons.

The cork planks are usually stacked in the field before being transported to the mill yard, although recently there has been a tendency to transport it immediately after extraction to the mill, avoiding storage in the field. Nowadays, this storage process takes about six months, although it may take longer.

Afterward, the cork planks are treated with non-chlorinated water in a closed stainlesssteel autoclave at $95^{\circ} \mathrm{C}$ for $1 \mathrm{~h}$. At the end of the process, these waters constitute a waste problem. Several studies have been devoted to its treatment in recent years with promising results [32-35].

The main objective of boiling is to change the mechanical properties of the cork planks to flatten them and facilitate subsequent cutting processes. After boiling, the planks are left to air dry for about 2-3 days, in what is called a stabilization step. Finally, it is passed through a cutter with a pair of rollers that leaves it completely flat on the inner side of the bark.

A more detailed description of the whole process can be found in Pereira [4].

\subsection{Testing Methodology}

Two alternative methods are commonly used to characterize the sound absorption of a material, the impedance tube [36] and the reverberation chamber [37]. While in the first case the incidence of sound waves is normal to the sample, it is random in the second one. The measured absorption properties in the second method are more representative of the performance of a material under real conditions in room acoustics and environmental applications $[29,38]$. In particular for natural virgin cork, since it presents many discontinuities of widely varying sizes when the outer bark faces upwards (Figure 1), the acoustic characterization of this material in the impedance tube using small samples could lead to misleading results. Experimental tests of different samples of natural virgin cork were carried out in this study to obtain their sound absorption coefficient $\left(\alpha_{s}\right)$ together with the practical $\left(\alpha_{p}\right)$ and weighted $\left(\alpha_{w}\right)$ sound absorption coefficients with random sound incidence following the specifications of ISO 354:2003 [37] and ISO 11654:1997 [39]. The results were compared with those obtained by alternative methods and the ASTM C423-17 standard [40]. 


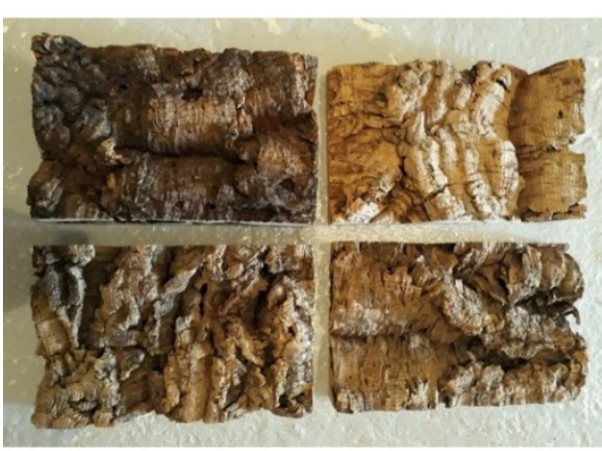

(a)

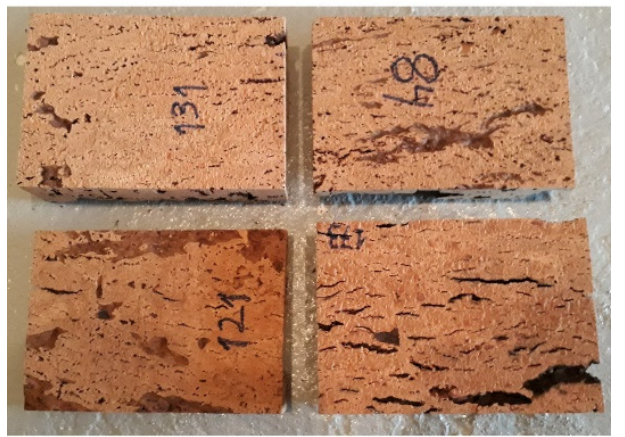

(b)

Figure 1. Different pieces of natural virgin cork where outer bark faces: (a) upwards; (b) downwards.

This study was performed in the normalized reverberation chamber located at the School of Technology of the University of Extremadura in Cáceres (Spain) [41], which was acoustically conditioned and satisfactorily complies with the requirements established in the ISO 354:2003 [37], ISO 3741:2010 [42], and ISO 3740:2019 [43]. The tests were carried out in accordance with ISO 354:2003 [37] using a Brüel and Kjær 2260 type 1 sound level meter with building acoustics software module, a Brüel and Kjær microphone type 4189, a Brüel and Kjær 4292 omnidirectional sound source, and a Lab Gruppen LAB 300 power amplifier.

The reverberation times (RT) were measured by the interrupted noise signal method using pink noise. The sound level meter was set to record data in one-third octave bands in a frequency range between $100 \mathrm{~Hz}$ and $5 \mathrm{kHz}$, and the average reverberation time of the 12 source-microphone combinations was obtained for each of the frequencies in the chosen range. Measurements of the reverberation time of the empty chamber were carried out on each test day. The temperature and relative humidity inside the chamber were within the ranges established by the ISO 354:2003 standard [37] during the tests $\left(>15^{\circ} \mathrm{C}\right.$ and $\left.30-90 \%\right)$.

\subsection{Samples Analyzed}

Different samples of natural virgin cork were configured for the tests, whose main characteristics are shown in Table 1. They were placed on the floor of the reverberation chamber in accordance with the type A mounting indicated in annex B of the ISO 354:2003 standard [37]. Samples S1 and S2 had an area of $10.2 \mathrm{~m}^{2}$ and their edges were covered with an acoustically reflective frame. In the first case (S1), the outer bark of the cork faced upwards, while in the second case (S2), the outer bark faced downwards. Sample S3 is a decorative absorber panel proposed as a final product for possible commercialization. Its exposed side had a majority composition of sample type $\mathrm{S} 1$ with decorative cork elements from sample type S2. According to the ISO 354 standard [37], if the edges of the sample are commonly exposed in a real application, they should not be covered during the test. Thus, the area of the edges was considered in the total surface area of the sample, resulting in a value of $10.1 \mathrm{~m}^{2}$. Samples S4, S5, S6, and S7 were other final product proposals for possible commercialization. They are other decorative combinations, similar to sample S3, but smaller to allow for modular installation. As in the previous case, their perimeter was not covered in the tests, and the area of the edges was considered in the total surface of the sample. Each of these four samples had a total surface area of $2.64 \mathrm{~m}^{2}$ and were manufactured in such a way that the exposed side had a majority composition of sample $\mathrm{S} 1$ with different decorative patterns of cork elements from sample S2. Figure 2 shows the samples tested in the experimental tests (Figure 2a-d) and some details of the samples S4, S5, S6, and S7 (Figure 2e-h). 
Table 1. Characteristics of the tested cork samples.

\begin{tabular}{|c|c|c|c|}
\hline Sample & Area $\left(m^{2}\right)$ & Average Thickness (cm) & Description \\
\hline S1 & 10.2 & 6 & Outer bark facing upwards \\
\hline $\mathrm{S} 2$ & 10.2 & 6 & Outer bark facing downwards \\
\hline S3 & 10.1 & 4 & $\begin{array}{c}\text { Panel with outer bark facing upwards (S1) with cork decorative } \\
\text { elements of S2 }\end{array}$ \\
\hline S4 & 2.64 & 4 & $\begin{array}{c}\text { Panel with outer bark facing upwards (S1) with diagonal decorative } \\
\text { elements of S2 }\end{array}$ \\
\hline S5 & 2.64 & 4 & $\begin{array}{c}\text { Panel with outer bark facing upwards (S1) with square decorative } \\
\text { elements of S2 }\end{array}$ \\
\hline S6 & 2.64 & 4 & $\begin{array}{c}\text { Panel with outer bark facing upwards (S1) with V-shaped decorative } \\
\text { elements of S2 }\end{array}$ \\
\hline S7 & 2.64 & 4 & $\begin{array}{c}\text { Panel with outer bark facing upwards (S1) with horizontal line } \\
\text { decorative elements of S2 }\end{array}$ \\
\hline
\end{tabular}

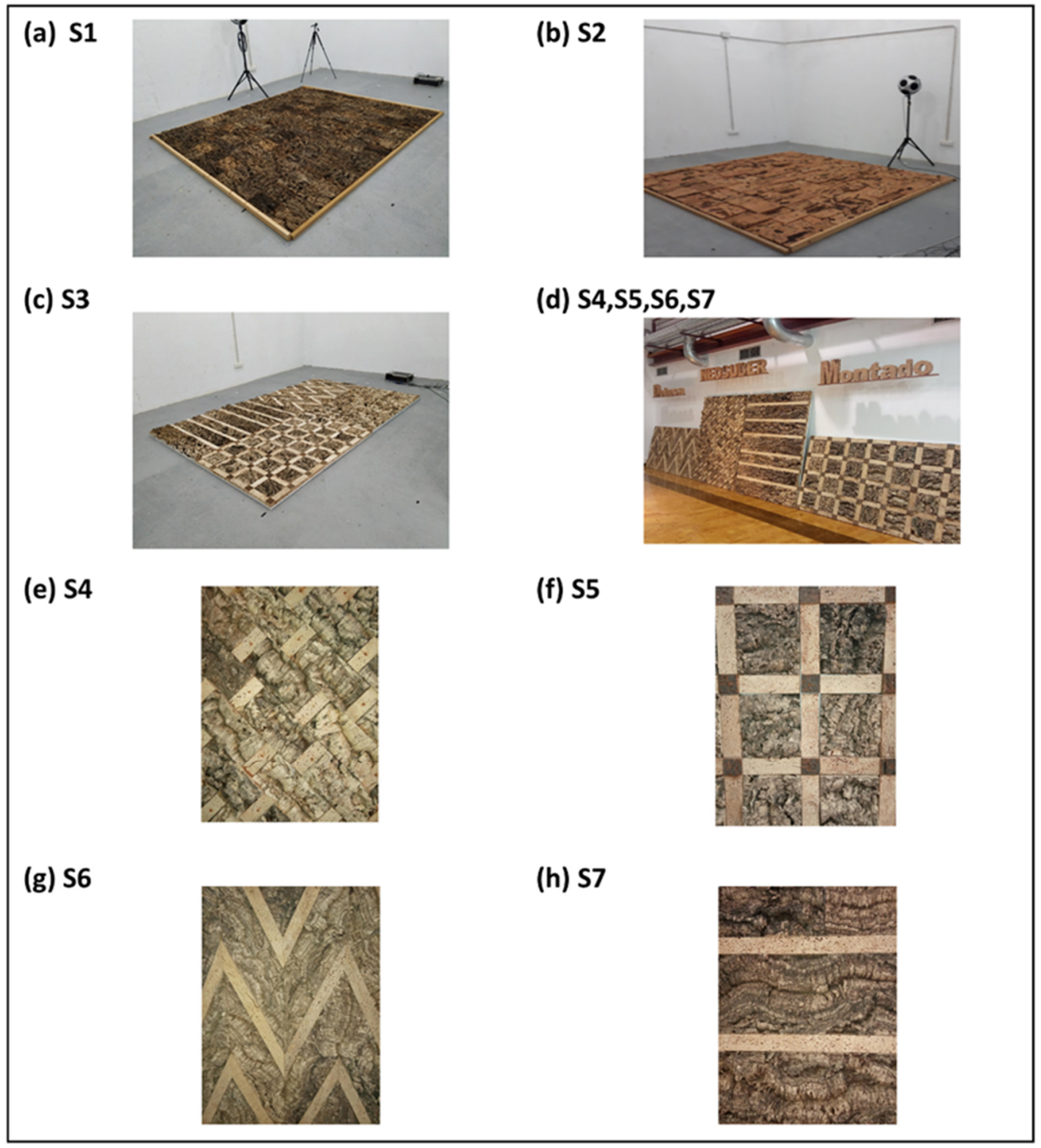

Figure 2. Samples tested in the reverberation chamber: (a) S1; (b) S2; (c) S3; (d) S4, S5, S6, and S7; and some details of the samples: S4 (e); S5 (f); S6 (g); S7 (h). 


\subsection{Calculation Method}

First, following the guidelines of ISO 354:2003 [37], the sound absorption coefficient $\left(\alpha_{s}\right)$ was obtained for each natural virgin cork sample using Equation (1), where $A_{T}$ is the equivalent sound absorption area and $S$ is the area of the test sample.

$$
\alpha_{S}=A_{T} / S
$$

Secondly, the weighted sound absorption coefficient $\left(\alpha_{w}\right)$ of each sample was obtained following the procedure established in ISO 11654 [39] from the sound absorption coefficients obtained in each frequency band. This standard indicates that the form factors must be given for those cases where the practical sound absorption coefficient $\left(\alpha_{p}\right)$ exceeds the value of the displaced reference curve by 0.25 or more. Thus, together with the value of $\alpha_{w}$, the notation $\mathrm{L}, \mathrm{M}$, and $\mathrm{H}$ was respectively specified when the excess occurs at $250 \mathrm{~Hz}$, 500 or $1000 \mathrm{~Hz}$, and 2000 or $4000 \mathrm{~Hz}$. From the value of $\alpha_{w}$, the tested sample could be classified into six different classes according to its absorption capacity (Table 2).

Table 2. Classification of the samples according to the weighted sound absorption coefficient $\left(\alpha_{w}\right)$ following ISO 11654.

\begin{tabular}{cc}
\hline Sound Absorption Classes & $\boldsymbol{\alpha}_{w}$ \\
\hline A & $0.90 ; 0.95 ; 1.00$ \\
B & $0.80 ; 0.85$ \\
C & $0.60 ; 0.65 ; 0.70 ; 0.75$ \\
D & $0.30 ; 0.35 ; 0.40 ; 0.45 ; 0.50 ; 0.55$ \\
E & $0.25 ; 0.20 ; 0.15$ \\
Unclassified & $0.10 ; 0.05 ; 0.00$ \\
\hline
\end{tabular}

\subsection{Sound Absorption Indexes According to the ASTM C423-17 Standard}

In order to evaluate the sound absorption capability of the samples, single number grading methods which are independent of frequencies were used. These indexes are useful for a practical evaluation of the performance of sound porous absorbers. The ASTM C423-17 standard [40] defines the Noise Reduction Coefficient (NRC) and the Sound Absorption Average (SAA) for this purpose. NRC is defined as the average of the sound absorption coefficients for 250,500,1000, and $2000 \mathrm{~Hz}$ rounded off to the nearest multiple of 0.05 . SAA is defined as the average of the sound absorption coefficients for 200, 250, 315, $400,500,630,800,1000,1250,1600,2000$, and $2500 \mathrm{~Hz}$, rounded off to the nearest 0.01 .

\section{Results and Discussion}

\subsection{Samples of Standardized Size}

Samples S1, S2, and S3 of natural virgin cork were tested in this section to obtain the different sound absorption coefficients. Figure 3 shows the sound absorption coefficient $\left(\alpha_{s}\right)$ in one-third octave bands (Figure 3a) and the practical sound absorption coefficient $\left(\alpha_{p}\right)$ in octave bands (Figure $3 b$ ) obtained for each of these samples, together with the expanded repeatability uncertainty for $95 \%$ confidence $\left(U_{\mathrm{r}}(95 \%)\right)$ calculated according to ISO 12999-2:2020 [44]. The results obtained for S1 show higher absorption than S2 at medium and high frequencies starting from the $800 \mathrm{~Hz}$ band, taking $\alpha_{s}$ values equal to or higher than 0.60 up to $5 \mathrm{kHz}$. However, the absorption at low and medium frequencies up to $500 \mathrm{~Hz}$ does not exceed the value of 0.25 . In the case of sample S2, the results obtained show a behavior of the absorption coefficient with higher values in the $500 \mathrm{~Hz}$ one-third octave band, where $\alpha_{s}$ reaches a value of 0.65 . Below the $400 \mathrm{~Hz}$ band, the coefficient takes values below 0.3, while, for frequencies above $630 \mathrm{~Hz}$, the value ranges between 0.3 and 0.4 . The differences found in the absorption curves of samples S1 and S2 would be due to the different surface structure of the top face of each sample (Figure 1a,b). Sample S1 presents a visible face with an irregular surface structure filled with cavities, compared to sample S2, which presents a much more uniform surface structure. These differences could explain 
the higher absorption in the 1 to $4 \mathrm{kHz}$ octave bands of sample S1. However, the behavior observed in the $500 \mathrm{~Hz}$ octave band, where sample S2 shows a higher absorption than S1, would require future investigations, either in a test chamber or in an impedance tube, to find the reasons for these differences, that could be related to the existence of an air layer underneath and the appearance of resonant effects. On the other hand, sample S3, corresponding to a decorative absorbing panel with an area of $10.1 \mathrm{~m}^{2}$ whose face exposed to view is composed mostly of exposed bark as in S1 with decorative cork elements as in sample S2, has a behavior closer to sample S1. However, it presents a higher absorption in the frequency bands between 200 and $500 \mathrm{~Hz}$, reaching a maximum difference of 0.17 at $400 \mathrm{~Hz}$ with respect to $\mathrm{S1}$, while the absorption curve is a little smoother in the frequency bands from 800 and $5000 \mathrm{~Hz}$. Similarly, Figure 3b shows the results obtained for $\alpha_{p}$ in octave bands between 250 and $4000 \mathrm{~Hz}$ according to ISO 11654 [39]. In general terms, the absorption curves for $\alpha_{p}$ present a similar shape to those obtained in Figure 3a for $\alpha_{s}$. Regarding the expanded uncertainty of $\alpha_{s}$ and $\alpha_{p}$, there are practically no differences between samples S1, S2, and S3. They all present the maximum uncertainty value in the $5 \mathrm{kHz}$ band, with a maximum value ranging between 0.08 and 0.09 depending on the sample.

Another comparison between samples S1, S2, and S3 can be made by considering global indicators of sound absorption (Table 3). First of all, if the indicators proposed by ISO 11654 [39] are considered, it is observed that the three samples show some differences with respect to the weighted sound absorption coefficient $\left(\alpha_{w}\right)$. Although S1 and S2 show the same value of 0.35 , the $\mathrm{MH}$ form factors in the case of $\mathrm{S} 1$ indicate a better performance in terms of sound absorption at medium $(500 \mathrm{~Hz}$ and $1 \mathrm{kHz})$ and high frequencies ( 2 and $4 \mathrm{kHz}$ ). In the case of $\mathrm{S} 3$, the sample presents an $\alpha_{w}$ value of 0.4 , which is slightly higher than the previous ones, and the $\mathrm{H}$ form factor, which means that the $\alpha_{p}$ values at high frequencies are considerably higher than those of the shifted reference curve. Despite these differences, all three samples have the same expanded repeatability uncertainty for $95 \%$ confidence and a type D sound absorption classification. On the other hand, if the NRC and SAA indicators proposed by ASTM C423-17 [40] are considered, it is observed that samples S1 and S3 present a higher sound absorption than S2, with sample S3 being the one that obtains better values for NRC.

Table 3. Sound absorption indicators for samples S1, S2, and S3.

\begin{tabular}{cccccc}
\hline Sample & $\alpha_{w}$ & $\mathbf{U}_{\mathbf{r}} \mathbf{( 9 5 \% )}$ & Sound Absorption Class & NRC & SAA \\
\hline S1 & $0.35(\mathrm{MH})$ & 0.04 & $\mathrm{D}$ & 0.40 & 0.42 \\
S2 & 0.35 & 0.04 & $\mathrm{D}$ & 0.35 & 0.35 \\
S3 & $0.40(\mathrm{H})$ & 0.04 & $\mathrm{D}$ & 0.45 & 0.42 \\
\hline
\end{tabular}

\subsection{Decorative Absorber Panels}

As previously indicated in the Section 2, samples S4, S5, S6, and S7 are samples of decorative absorbent panels manufactured as final product proposals for possible commercialization, but with a smaller size than sample S3 in order to allow for a modular installation. In all of them, the exposed face is mostly composed of exposed bark as in sample S1 and the only variation between samples is the decorative pattern of the normal cork elements as in sample S2. Figure 4 presents the sound absorption coefficient $\left(\alpha_{s}\right)$ in one-third octave bands (Figure $4 \mathrm{a}$ ) and the practical sound absorption coefficient $\left(\alpha_{p}\right)$ in octave bands (Figure $4 \mathrm{~b}$ ) obtained for each of these samples, along with the expanded repeatability uncertainty for $95 \%$ confidence $\left(U_{r}(95 \%)\right)$. It can be observed how, starting from the $250 \mathrm{~Hz}$ band, the absorption of these samples increases progressively with frequency up to $800 \mathrm{~Hz}$ and similarly, although S6 and S7 present slightly better absorbing behavior than S4 and S5 in this frequency range. Starting at $1 \mathrm{kHz}$, samples S4, S5, and S7 follow a similar trend with $\alpha_{s}$ values generally ranging between 0.6 and 0.75 . However, sample S6 presents slightly lower values in this frequency range, with values between approximately 0.5 and 0.6. In the case of $\alpha_{p}$ in octave bands, the trend of the absorption curve is similar to 
that of $\alpha_{s}$. The expanded uncertainty of $\alpha_{s}$ and $\alpha_{p}$ shows no differences among the four samples studied, presenting a maximum of approximately 0.1 in the $5 \mathrm{kHz}$ band.

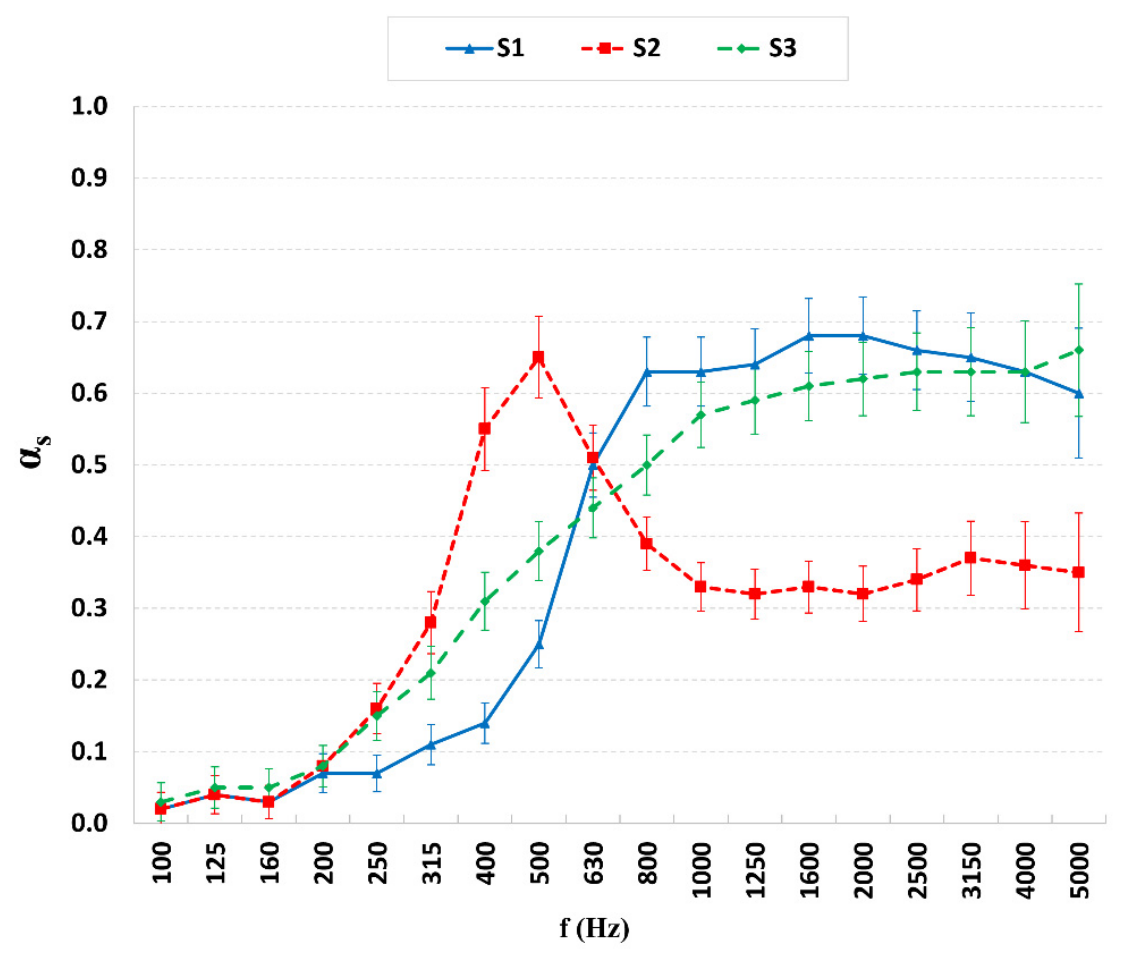

(a)

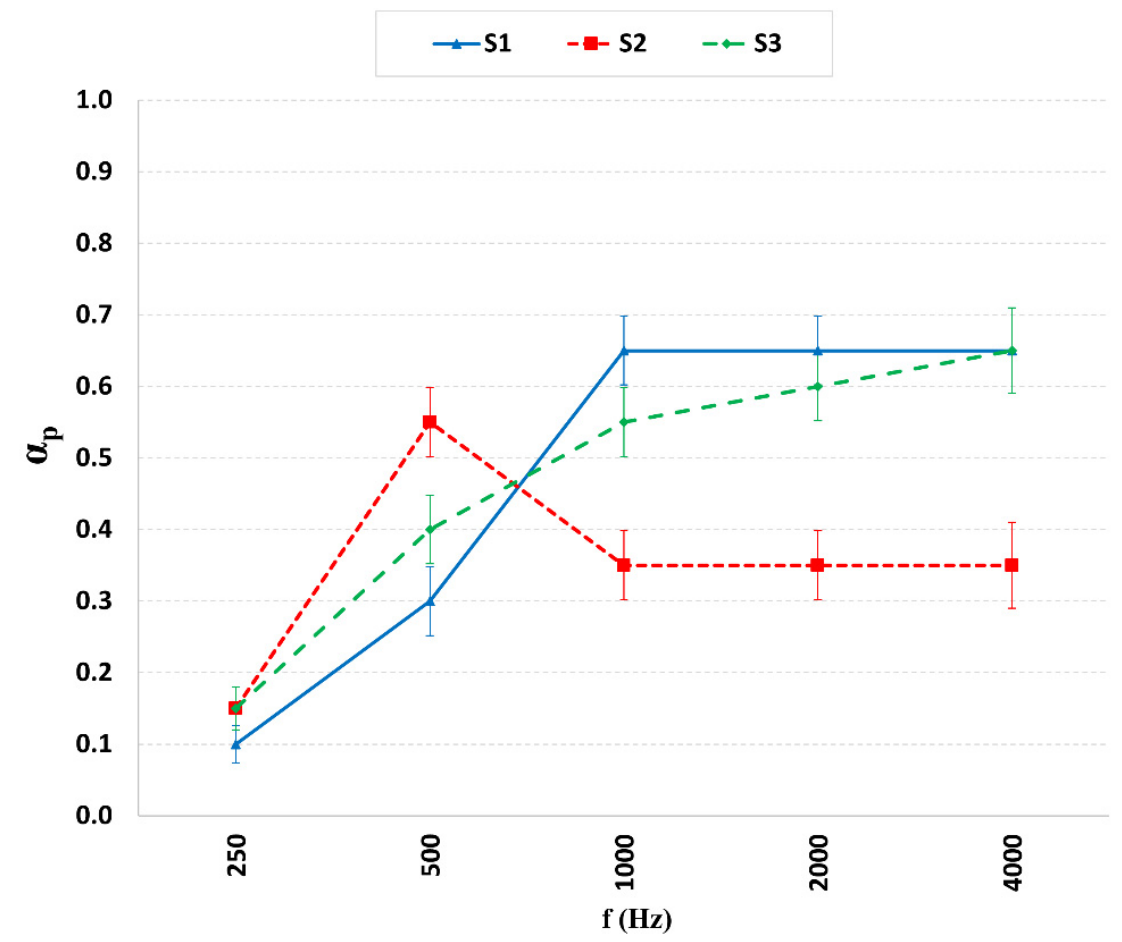

(b)

Figure 3. Sound absorption coefficients for samples S1, S2, and S3: (a) $\alpha_{s}$; (b) $\alpha_{p}$. 


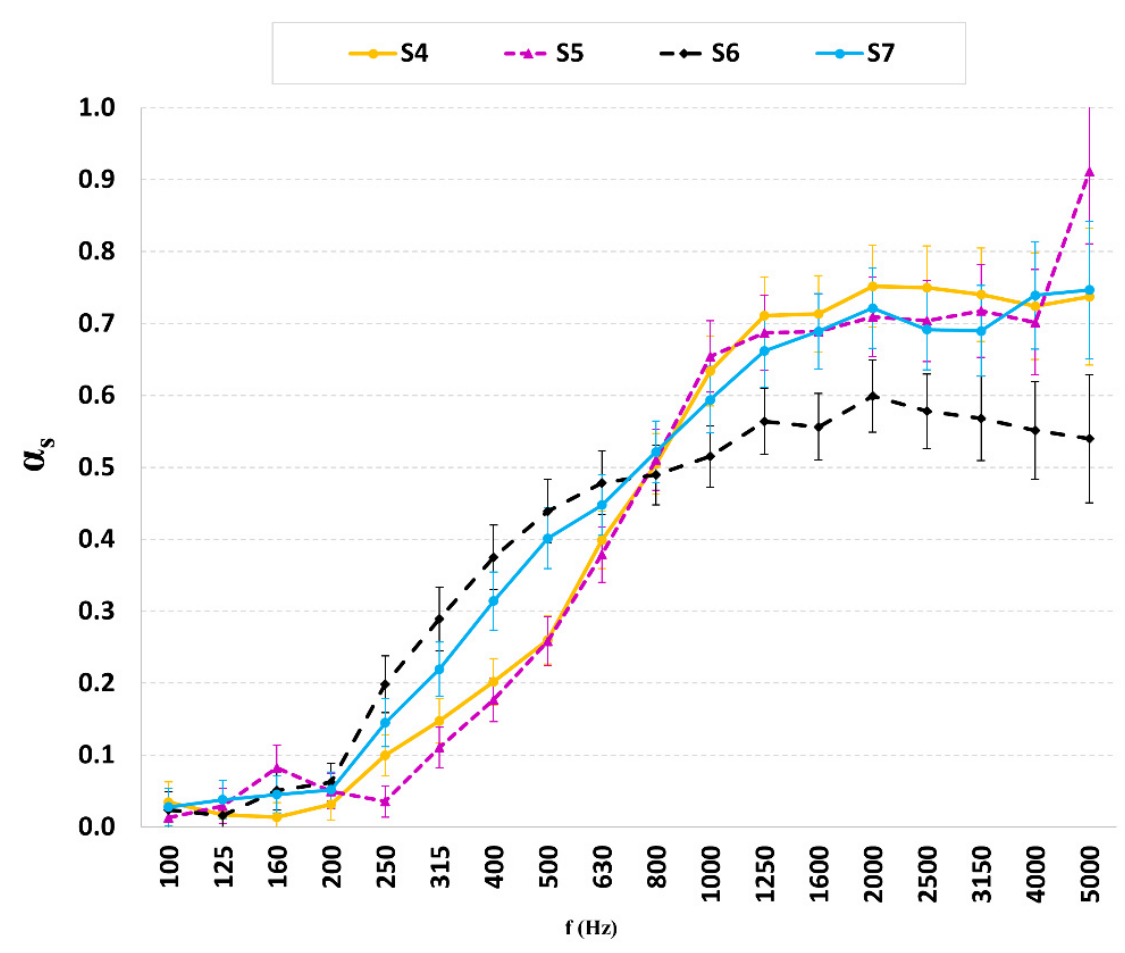

(a)

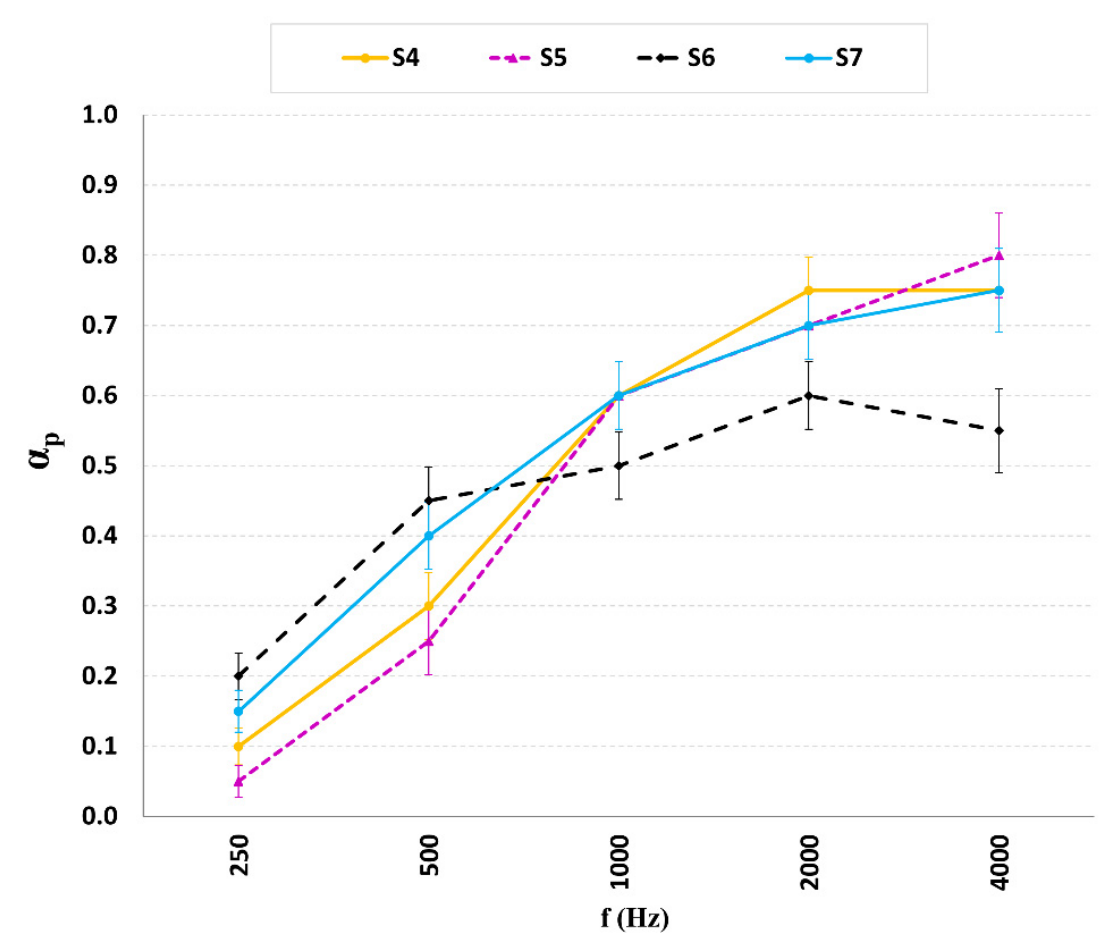

(b)

Figure 4. Sound absorption coefficients for samples S4, S5, S6, and S7: (a) $\alpha_{s} ;$ (b) $\alpha_{p}$.

If a comparison is made between samples S4, S5, S6, and S7 from ISO 11654 [39] global sound absorption indicators (Table 4 ), the weighted sound absorption coefficient $\left(\alpha_{w}\right)$ of the different samples ranges from 0.3 to 0.45 . Sample $\mathrm{S} 6$ shows the highest value, however, the form factors of the other three samples indicate that the $\alpha_{p}$ values are considerably higher than those of the shifted reference curve at medium $(\mathrm{M})$ and/or high $(\mathrm{H})$ frequencies, as 
appropriate. The differences in $\alpha_{w}$ and in the form factors of each sample do not result in a different sound absorption classification or in a variation of the expanded repeatability uncertainty. On the other hand, if a comparison is made from the NRC and SAA indicators of ASTM C423-17 [40], a more similar absorbent behavior of all samples is found. In this case, sample S7 presents a slightly higher SAA value.

Table 4. Sound absorption indicators for samples S4, S5, S6, and S7.

\begin{tabular}{cccccc}
\hline Sample & $\boldsymbol{\alpha}_{w}$ & $\mathbf{U}_{\mathbf{r}} \mathbf{( 9 5 \% )}$ & Sound Absorption Class & NRC & SAA \\
\hline S4 & $0.35(\mathrm{MH})$ & 0.04 & $\mathrm{D}$ & 0.45 & 0.43 \\
S5 & $0.30(\mathrm{MH})$ & 0.04 & $\mathrm{D}$ & 0.40 & 0.41 \\
S6 & 0.45 & 0.04 & $\mathrm{D}$ & 0.45 & 0.43 \\
S7 & $0.40(\mathrm{H})$ & 0.04 & $\mathrm{D}$ & 0.45 & 0.45 \\
\hline
\end{tabular}

\subsection{Comparison with Other Recycled Materials}

Given the described growing need for the use of sustainable materials, it was considered of interest to make a comparison of these samples of natural virgin cork with some recycled materials tested in a standardized reverberation chamber and with similar sample sizes. Figure 5a shows the results obtained for the sound absorption coefficient $\left(\alpha_{s}\right)$ and Figure $5 \mathrm{~b}$ shows the practical sound absorption coefficient $\left(\alpha_{p}\right)$, together with the expanded repeatability uncertainty for $95 \%$ confidence $\left(\mathrm{U}_{\mathrm{r}}(95 \%)\right)$, for samples of materials such as sheep wool mixed with PET as a binder [29] and PET ( $40 \mathrm{~mm}$ thick and $\left.1400 \mathrm{~g} / \mathrm{m}^{2}\right)$ from recycled bottles [24], in addition to samples S1, S2, and S3 of natural virgin cork. We have not found any other published works in the scientific literature on natural or recycled materials studied in standardized reverberation chambers. The values of $\alpha_{s}$ (Figure 5a) and $\alpha_{p}$ (Figure $5 b$ ) show that both the sheep wool and PET samples present a better absorbing behavior than samples S1, S2, and S3 of natural virgin cork in the whole frequency range. Sheep wool also has higher absorption coefficients than PET for medium and high frequencies. It is in the high-frequency range where natural virgin cork samples S1 and S3 approach the absorption curve of PET, while sample S2 reaches values similar to those of sheep wool and PET in the 400 and $500 \mathrm{~Hz}$ bands. If the global sound absorption indicators of Table 5 such as $\alpha_{w}$, NRC, and SAA are also considered in the analysis, it is observed that the sound absorption capacity of the natural virgin cork samples is lower than those of sheep wool and PET.

Table 5. Sound absorption indicators for some samples.

\begin{tabular}{cccccc}
\hline Sample & $\boldsymbol{\alpha}_{\boldsymbol{w}}$ & $\mathbf{U}_{\mathbf{r}} \mathbf{( 9 5 \% )}$ & Sound Absorption Class & NRC & SAA \\
\hline Sheep Wool & 0.75 & 0.04 & $\mathrm{C}$ & 0.70 & 0.70 \\
PET & $0.70(\mathrm{H})$ & 0.04 & $\mathrm{C}$ & 0.60 & 0.62 \\
Virgin cork (S1) & $0.35(\mathrm{MH})$ & 0.04 & $\mathrm{D}$ & 0.40 & 0.42 \\
Virgin cork (S2) & 0.35 & 0.04 & $\mathrm{D}$ & 0.35 & 0.35 \\
Virgin cork (S3) & $0.40(\mathrm{H})$ & 0.04 & $\mathrm{D}$ & 0.45 & 0.42 \\
\hline
\end{tabular}

Two options can be considered taking into account the actual possible applications of these materials as acoustic absorbers. On the one hand, materials with absorbing properties are usually used inside double walls in order to reduce the effect of coupling by standing waves in the cavity and, therefore, increase acoustic insulation, or within perforated panels in acoustic screens. In this type of application, considering the values of the absorption coefficients of the different materials and the final objective pursued, in general, the use of sheep wool or PET can be more interesting than the use of virgin cork. Although, in a more complete analysis, other criteria related to the on-site installation process, production costs, sustainability, etc. should also be included. In this sense, it should be noted that the virgin cork studied is a fully ecological material, not recycled, with no added agglomerating 
products and with little water treatment, which has been considered a waste material until now but can have a quite interesting acoustic use.

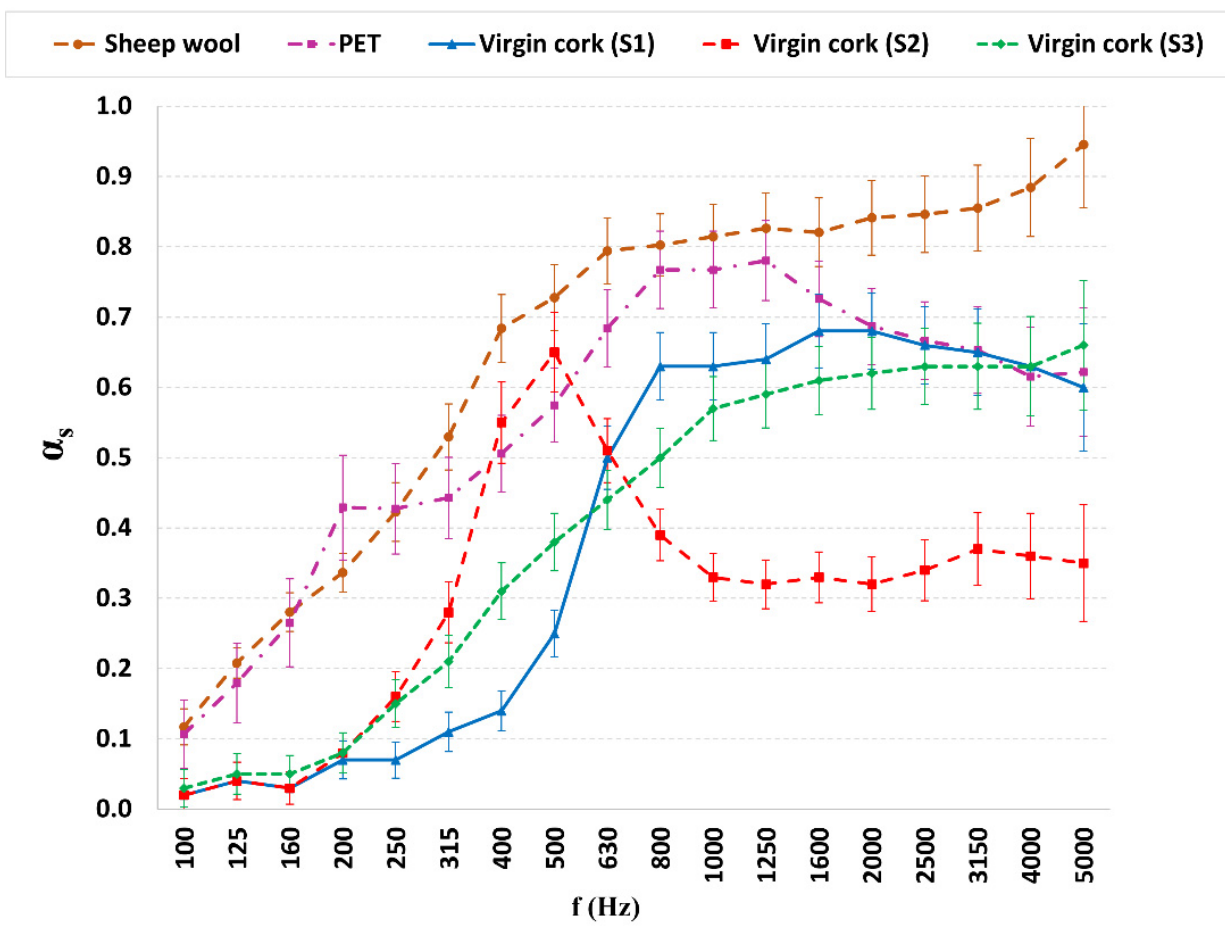

(a)

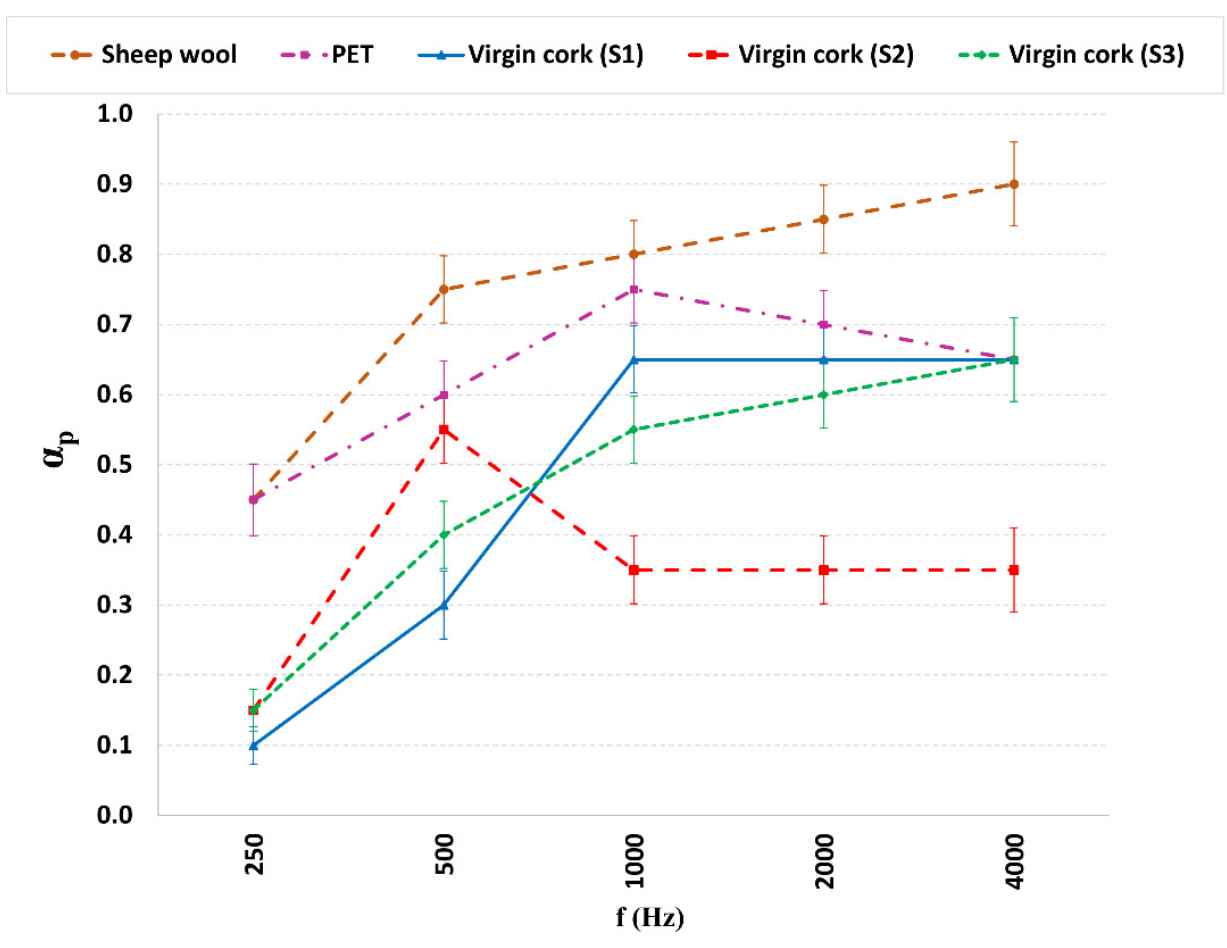

(b)

Figure 5. Sound absorption coefficients for some samples: (a) $\alpha_{s} ;$ (b) $\alpha_{p}$.

These materials are also used as acoustic absorbers in the vertical and horizontal walls of interior spaces to reduce the reverberation time and improve the sensation of acoustic 
comfort. Theatres, auditoriums, concert halls, conference halls, etc. are types of enclosures that require specific room conditioning according to their use. Some international standards recommend values for reverberation time in certain types of enclosures [45]. The use of absorbers in these spaces, therefore, requires a format with decorative characteristics in accordance with those of the enclosure. In this case, the natural virgin cork samples S3, S4, S5, S6, and S7 could have a greater interest of use, since they represent final proposals of absorbent decorative panels for their possible commercialization. In addition, their production process is simple and energetically sustainable since they do not require any added treatment and directly present their own aesthetics.

\section{Conclusions}

This article presents a study to characterize the sound absorption of a sustainable and currently little-used material, natural virgin cork, in order to explore other possible uses of this material with a low carbon footprint and reduced cost in the design of acoustic solutions for insulation, conditioning, and noise control.

Different samples of virgin cork not bonded were tested under random sound incidence conditions in a standardized reverberation chamber according to ISO 354 . The samples in which the outer bark of the cork was facing upwards showed better behavior as an acoustic absorber, with values of the absorption coefficients $\alpha_{s}$ and $\alpha_{p}$ equal to or greater than 0.6 for frequency bands between 1 and $5 \mathrm{kHz}$.

Several proposals for decorative absorbent panels were also studied as final products for modular installation in those enclosures where room conditioning is desired to reduce reverberation time. Similar results were obtained for the four-panel formats studied for the absorption coefficients $\alpha_{s}$ and $\alpha_{p}$, although with slight variations between them in the medium and high-frequency ranges.

A comparison of its behavior as an acoustic absorber was carried out with respect to other recycled materials tested in a standardized reverberation chamber, such as sheep wool mixed with PET as a binder and PET from recycled bottles. Different indicators show that the sheep wool and PET samples present a better absorbing behavior than the natural virgin cork samples in the whole frequency range. However, it should be noted that not all samples can be considered as final products for installation as an in-situ sound absorber, as in some cases the customization process could lead to some modifications in the absorbing behavior. In this sense, the choice of one material or another for the different types of acoustic solutions for insulation, conditioning, and noise control may depend not only on purely acoustic criteria, but also on other criteria associated with on-site installation, production costs, sustainability, aesthetics, etc.

Author Contributions: Conceptualization, J.M.B.M.; methodology, J.M.B.M., D.M.G., R.V.-G. and V.G.E.; validation, J.M.B.M., D.M.G., R.V.-G., V.G.E. and R.M.-S.; formal analysis, J.M.B.M., D.M.G., R.V.-G., V.G.E. and R.M.-S.; investigation, J.M.B.M., D.M.G., R.V.-G., V.G.E., R.M.-S., G.R.G. and P.A.M.; resources, J.M.B.M.; data curation, J.M.B.M., D.M.G., R.V.-G., V.G.E. and P.A.M.; writingoriginal draft preparation, J.M.B.M., D.M.G., R.V.-G., V.G.E. and R.M.-S.; writing-review and editing, J.M.B.M., D.M.G., R.V.-G., V.G.E., R.M.-S. and G.R.G.; visualization, J.M.B.M., D.M.G., R.V.-G., V.G.E., R.M.-S., G.R.G. and P.A.M.; supervision, J.M.B.M., D.M.G., R.V.-G., V.G.E., R.M.-S. and G.R.G.; project administration, J.M.B.M.; funding acquisition, J.M.B.M., D.M.G. and G.R.G. All authors have read and agreed to the published version of the manuscript.

Funding: This project was co-financed by the European Regional Development Fund (ERDF) and Junta de Extremadura (GR18107 and IB18050). This work was also supported by Consejería de Economía, Ciencia, y Agenda Digital of Junta de Extremadura, the European Union, and the European Social Fund (ESF) through grants for the strengthening of R\&D\&I through the mobility of postdoctoral researchers (PO17014) and by Consejería de Economía, Ciencia y Agenda Digital of Junta de Extremadura through grants for attracting and returning research talent to R\&D\&I centers belonging to the Extremadura Science, Technology, and Innovation System (TA18019), where the University of Extremadura was the beneficiary entity in both cases.

Institutional Review Board Statement: Not applicable. 
Informed Consent Statement: Not applicable.

Acknowledgments: The authors would like to thank the NEOSUBER project "Adaptive forestry for dehesas in Extremadura. New virgin cork uses", coordinated by CICYTEX (Center for Scientific and Technological Research in Extremadura) and co-financed by the European Union through the European Regional Development Fund (FEDER), and Junta de Extremadura, for providing the cork samples for the experimental tests.

Conflicts of Interest: The authors declare no conflict of interest.

\section{References}

1. Duarte, A.P.; Bordado, J.C. Cork-A renewable raw material: Forecast of industrial potential and development priorities. Front. Mater. 2015, 2, 1-8. [CrossRef]

2. Rives, J.; Fernandez-Rodriguez, I.; Rieradevall, J.; Gabarrell, X. Environmental analysis of raw cork extraction in cork oak forests in southern Europe (Catalonia-Spain). J. Environ. Manag. 2012, 110, 236-245. [CrossRef] [PubMed]

3. ISO 633:2019. Cork—Vocabulary; International Organization for Standardization: Geneva, Switzerland, 2019.

4. Pereira, H. Cork: Biology, Production and Uses; Elsevier: Lisbon, Portugal, 2007; p. 336, ISBN 13-978-0-444-52967-1.

5. Silva, S.P.; Sabino, M.A.; Fernandas, E.M.; Correlo, V.M.; Boesel, L.F.; Reis, R.L. Cork: Properties, capabilities and applications. Int. Mater. Rev. 2005, 50, 345-365. [CrossRef]

6. Knapic, S.; Oliveira, V.; Machado, J.S.; Pereira, H. Cork as a building material: A review. Eur. J. Wood Wood Prod. 2016, 74, 775-791. [CrossRef]

7. Kounina, A.; Tatti, E.; Humbert, S.; Pfister, R.; Pike, A.; Ménard, J.-F.; Loerincik, Y.; Jolliet, O. The Importance of Considering Product Loss Rates in Life Cycle Assessment: The Example of Closure Systems for Bottled Wine. Sustainability 2012, 4, $2673-2706$. [CrossRef]

8. Parra, C.; Sánchez, E.M.; Miñano, I.; Benito, F.; Hidalgo, P. Recycled Plastic and Cork Waste for Structural Lightweight Concrete Production. Sustainability 2019, 11, 1876. [CrossRef]

9. Pacheco Menor, M.C.; Serna Ros, P.; Macías García, A.; Arévalo Caballero, M.J. Granulated cork with bark characterised as environment-friendly lightweight aggregate for cement based materials. J. Clean. Prod. 2019, 229, 358-373. [CrossRef]

10. Pereira, H.; Ferreira, E. Scanning electron microscopy observations of insulation cork agglomerates. Mater. Sci. Eng. A 1989, 111, 217-225. [CrossRef]

11. EEA. Environmental Noise in Europe-2020; European Environment Agency: København, Denmark; Publications Office of the European Union: Luxembourg, 2020. Available online: https://www.eea.europa.eu/publications/environmental-noise-ineurope (accessed on 25 March 2021).

12. Park, T.; Kim, M.; Jang, C.; Choung, T.; Sim, K.-A.; Seo, D.; Chang, S.I. The Public Health Impact of Road-Traffic Noise in a Highly-Populated City, Republic of Korea: Annoyance and Sleep Disturbance. Sustainability 2018, 10, 2947. [CrossRef]

13. Fediuk, R.; Amran, M.; Vatin, N.; Vasilev, Y.; Lesovik, V.; Ozbakkaloglu, T. Acoustic Properties of Innovative Concretes: A Review. Materials 2021, 14, 398. [CrossRef]

14. Azkorra, Z.; Pérez, G.; Coma, J.; Cabeza, L.F.; Bures, S.; Álvaro, J.E.; Erkoreka, A.; Urrestarazu, M. Evaluation of green walls as a passive acoustic insulation system for buildings. Appl. Acoust. 2015, 89, 46-56. [CrossRef]

15. Torresin, S.; Albatici, R.; Aletta, F.; Babich, F.; Kang, J. Assessment Methods and Factors Determining Positive Indoor Soundscapes in Residential Buildings: A Systematic Review. Sustainability 2019, 11, 5290. [CrossRef]

16. Lauria, A.; Secchi, S.; Vessella, L. Acoustic Comfort as a Salutogenic Resource in Learning Environments-A Proposal for the Design of a System to Improve the Acoustic Quality of Classrooms. Sustainability 2020, 12, 9733. [CrossRef]

17. Cantero, B.; Sáez del Bosque, I.F.; Matías, A.; Sánchez de Rojas, M.I.; Medina, C. Water transport mechanisms in concretes bearing mixed recycled aggregates. Cem. Concr. Compos. 2020, 107, 103486. [CrossRef]

18. Gómez Escobar, V.; Rey Gozalo, G.; Pérez, C.J. Variability and performance study of the sound absorption of used cigarette butts. Materials 2019, 12, 2584. [CrossRef] [PubMed]

19. Khan, A.; Mohamed, M.; Al Halo, N.; Benkreira, H. Acoustical properties of novel sound absorbers made from recycled granulates. Appl. Acoust. 2017, 127, 80-88. [CrossRef]

20. Maderuelo-Sanz, R.; Martin-Castizo, M.; Vílchez-Gómez, R. The performance of resilient layers made from recycled rubber fluff for impact noise reduction. Appl. Acoust. 2011, 72, 823-828. [CrossRef]

21. Maderuelo-Sanz, R.; Gómez Escobar, V.; Meneses-Rodríguez, J.M. Potential use of cigarette filters as sound porous absorber. Appl. Acoust. 2018, 129, 86-91. [CrossRef]

22. Martellotta, F.; Cannavale, A.; De Matteis, V.; Ayr, U. Sustainable sound absorbers obtained from olive pruning wastes and chitosan binder. Appl. Acoust. 2018, 141, 71-78. [CrossRef]

23. Mohajerani, A.; Kadir, A.A.; Larobina, L. A practical proposal for solving the world's cigarette butt problem: Recycling in fired clay bricks. Waste Manag. 2016, 52, 228-244. [CrossRef]

24. Del Rey, R.; Alba, J.; Ramis, J.; Sanchis, V.J. New absorbent acoustic materials from plastic bottle remnants. Mater. Constr. 2011, 61, 547-558. [CrossRef] 
25. Adhika, D.R.; Prasetiyo, I.; Noeriman, A.; Hidayah, N.; Widayani, S. Sound absorption characteristics of pineapple leaf/epoxy composite. Arch. Acoust. 2020, 45, 233-240. [CrossRef]

26. Bhattacharya, S.S.; Bihola, D.V. Acoustic properties of kapok fibre. Int. J. Eng. Adv. Technol. 2019, 9, 2164-2168. [CrossRef]

27. Glé, P.; Gourdon, E.; Arnaud, L. Acoustical properties of materials made of vegetable particles with several scales of porosity. Appl. Acoust. 2011, 72, 249-259. [CrossRef]

28. Berardi, U.; Iannace, G. Acoustic characterization of natural fibers for sound absorption applications. Build. Environ. 2015, 94, 840-852. [CrossRef]

29. Del Rey, R.; Uris, A.; Alba, J.; Candelas, P. Characterization of sheep wool as a sustainable material for acoustic applications. Materials 2017, 10, 1277. [CrossRef] [PubMed]

30. Maderuelo-Sanz, R.; Barrigón Morillas, J.M.; Gómez Escobar, V. Acoustical performance of loose cork granulates. Eur. J. Wood Wood Prod. 2014, 72, 321-330. [CrossRef]

31. Maderuelo-Sanz, R.; Barrigón Morillas, J.M.; Gómez Escobar, V. The performance of resilient layers made from cork granulates mixed with resins for impact noise reduction. Eur. J. Wood Wood Prod. 2014, 72, 833-835. [CrossRef]

32. Arshadi, M.; Attard, T.M.; Lukasik, R.M.; Brncic, M.; da Costa Lopes, A.M.; Finell, M.; Geladi, P.; Gerchesnon, L.M.; Gogus, F.; Herrero, M.; et al. Pre-treatment and extraction techniques for recovery of added value compounds from wastes throughout the agri-food chain. Green Chem. 2016, 18, 6160-6204. [CrossRef]

33. Gomes, L.; Borges, C.; Serralheiro, M.L.M.; Minhalma, M.; Pacheco, R. Cork processing wastewaters components fractioned by ultrafiltration membranes-studies of antioxidant and antitumoral activity. J. Chem. Technol. Biotechnol. 2018, 93, 861-870. [CrossRef]

34. Ponce-Robles, L.; Miralles-Cuevas, S.; Oller, I.; Agüera, A.; Trinidad-Lozano, M.J.; Yuste, F.J.; Malato, S. Cork boiling wastewater treatment and reuse through combination of advanced oxidation technologies. Environ. Sci. Pollut. Res. 2017, 24, 6317-6328. [CrossRef] [PubMed]

35. Wu, Z.; Yuste-Córdoba, F.J.; Cintas, P.; Wu, Z.; Boffa, L.; Mantegna, S.; Cravotto, G. Effects of ultrasonic and hydrodynamic cavitation on the treatment of cork wastewater by flocculation and Fenton processes. Ultrason. Sonochem. 2018, 40, 3-8. [CrossRef] [PubMed]

36. ISO 10534-2. Acoustics-Determination of Sound Absorption Coefficient and Impedance in Impedances Tubes-Part 2: Transfer-Function Method; International Organization for Standardization: Geneva, Switzerland, 1998.

37. ISO 354. Acoustics-Measurement of Sound Absorption in a Reverberation Room; International Organization for Standardization: Geneva, Switzerland, 2003.

38. Oldham, D.J.; Egan, C.A.; Cookson, R.D. Sustainable acoustic absorbers from the biomass. Appl. Acoust. 2011, 72, 350-363. [CrossRef]

39. ISO 11654. Acoustics-Sound Absorbers for Use in Buildings. Rating of Sound Absorption; International Organization for Standardization: Geneva, Switzerland, 1997.

40. ASTM C423-17. Standard Test Method for Sound Absorption and Sound Absorption Coefficients by the Reverberation Room Method; ASTM Standard; ASTM International: West Conshohocken, PA, USA, 2017. [CrossRef]

41. Prieto Gajardo, C.; Barrigón Morillas, J.M.; Vílchez-Gómez, R.; Gómez Escobar, V.; Rey Gozalo, G.; Méndez Sierra, J.A.; Carmona del Río, F.J. Acondicionamiento de la cámara reverberante de la Universidad de Extremadura. In Proceedings of the VIII Congreso Iberoamericano de Acústica, Evora, Portugal, 1-3 October 2012.

42. ISO 3741. Acoustics-Determination of Sound Power Levels and Sound Energy Levels of Noise Sources Using Sound Pressure. Precision Methods for Reverberation Test Rooms; International Organization for Standardization: Geneva, Switzerland, 2010.

43. ISO 3740. Acoustics—Determination of Sound Power Levels of Noise Sources. Guidelines for the Use of Basic Standards; International Organization for Standardization: Geneva, Switzerland, 2019.

44. ISO 12999-2. Acoustics-Determination and Application of Measurement Uncertainties in Building Acoustics. Part 2: Sound Absorption; International Organization for Standardization: Geneva, Switzerland, 2020.

45. ANSI/ASA 512.60. Acoustical Performance Criteria, Design Requirements, and Guidelines for Schools. Part 1: Permanent Schools; American National Standards Institute, Inc.: New York, NY, USA; Acoustical Society of America: Melville, NY, USA, 2010. 